\title{
A EXPLORAÇÃo SUBJACENTE AO CICLO DO CAPITAL MONETÁRIO
}

\author{
Mailson Bruno de Queiroz Carneiro Gonçalves ${ }^{1}$ \\ Eduardo Ferreira Chagas ${ }^{2}$
}

\begin{abstract}
Resumo:
O objetivo deste artigo é revelar a exploração imanente ao conjunto de metamorfoses inscritas no ciclo do capital monetário. A compra dos elementos produtivos no mercado, cuja fórmula consiste na série D-M, corresponde ao primeiro estágio de um circuito cuja finalidade é a acumulação representada na forma dinheiro. Mais do que a subordinação formal da força de trabalho, a operação D-T garante, com o devido reconhecimento legal, a extração do mais-valor, absorvido sucessivamente na esfera da circulação após o cumprimento de M'-D'. Camuflada pela igualdade abstrata do direito burguês, a venda da força de trabalho tem como pressuposto a expropriação, tanto despojando os produtores dos seus meios de subsistência como através da pilhagem materializada na forma salário.
\end{abstract}

Palavras-chave: Marx. Exploração. Capital Monetário.

\section{THE EXPLORATION UNDERLYING THE MONETARY CAPITAL CYCLE}

\begin{abstract}
:
The purpose of this article is to reveal the exploration immanent to the set of metamorphoses inscribed in the cycle of monetary capital. The purchase of productive elements on the market, whose formula consists of the D-M series, corresponds to the first stage of a circuit whose purpose is the accumulation represented in the form of money. More than the formal subordination of the workforce, the D-T operation guarantees, with due legal recognition, the extraction of the surplus value, absorbed successively in the sphere of circulation after the fulfilment of M'-D'. Camouflaged by the abstract equality of bourgeois law, the sale of the labour force is based on expropriation, both depriving producers of their means of subsistence and through materialized looting in the form of wages.
\end{abstract}

Keywords: Marx. Exploration. Monetary Capital.

Marx (2014) inicia sua exposição sobre a circulação do capital apontando os três estágios que constituem o processo cíclico da produção capitalista: 1) a transformação do dinheiro em mercadoria; 2) o consumo da mercadoria durante a produção; 3) a venda da mercadoria com mais-valor obtida através do metabolismo

1 Possui graduação em Comunicação Social com habilitação em Jornalismo pela Universidade de Fortaleza/UNIFOR (2013). Bacharel em História pela Universidade Federal do Ceará/UFC (2017), graduando em Filosofia pela Universidade Estadual do Ceará/UECE (2017-2020), Mestre em Filosofia pela Universidade Federal do Ceará/UFC (2019). Doutorando em Filosofia pela Universidade Federal do Ceará/UFC (2020-2024). E-mail: bruno.qcg@ outlook.com.br.

2 Pós-Doctor em Filosofia pela Universität von Münster (Alemanha) (2019); Doutor em Filosofia pela Universität von Kassel (Alemanha) (2002); Mestrado em Filosofia pela Faculdade de Filosofia e Ciências Humanas (FAFICH) da Universidade Federal de Minas Gerais (UFMG, 1993); Graduado em Filosofia pela Universidade Estadual do Ceará (UECE, 1989). É professor efetivo (associado) do Curso de Filosofia e do Programa de Pós-Graduação em Filosofia da Universidade Federal do Ceará (UFC) e Professor Colaborador do Programa de Pós-Graduação em Educação Brasileira da FACED UFC. Atualmente, é pesquisador bolsista de produtividade CNPQ. E-mail: ef.chagas@uol.com.br. 
entre meios de produção e força de trabalho. Em sua análise das leis que regem a economia burguesa, Marx expôs de forma mais ampla e sistemática apenas o segundo estágio do circuito. Cabe agora demonstrar o funcionamento das séries cuja inserção no livro I limitava-se à compreensão do processo de produção do mais-valor. Vejamos como Engels (2014, p. 107) descreve a sucessão do dinheiro, isto é, o ciclo do capital monetário: “A fórmula para o ciclo do capital monetário é, portanto: D-M...P...M'D', sendo que os pontos significam que o processo de circulação foi interrompido, e M' e D' indicam M e D aumentados pelo mais-valor".

Marx introduz o ciclo do capital monetário retomando a relação de troca cujo nexo foi explicitado no capítulo 3 do livro I, intitulado $O$ dinheiro ou a circulação de mercadorias $^{3}$. Segundo o autor, o primeiro estágio da fórmula que tem como ponto de partida o capital monetário encontra sua expressão no circuito D-M, isto é, na transformação do dinheiro em mercadoria, cuja plenitude contempla a unidade força de trabalho $\mathrm{T}$ e meios de produção $\mathrm{Mp}$, conforme é apresentado na seguinte equação: $\mathrm{M}=$ $\mathrm{T}+\mathrm{Mp}$.

A quantia de dinheiro D se divide em duas partes, das quais uma compra força de trabalho e a outra, meios de produção. Essas duas séries de compras pertencem a mercados absolutamente distintos: um ao mercado de mercadorias propriamente dito, e a outra, ao mercado de trabalho. (MARX, 2014, p. 108).

A execução do estágio D-M, isto é, a compra de capital constante e capital variável mediante o feitiço do dinheiro, é composta por duas operações distintas, porém interdependentes, de modo que a passagem da forma valor, representada pela combinação entre meios de produção $\mathrm{Mp}$ e força de trabalho $\mathrm{T}$, pressupõe uma adequação entre seus substratos materiais. Essa metamorfose tem como propósito extrair o mais-valor necessário à produção capitalista, cujo fundamento, conforme foi demonstrado no livro I, consiste no esgotamento físico e mental dos trabalhadores. O capital, como um parasita insaciável, absorve o sangue retirado do hospedeiro enquanto princípio da sede vampiresca que lhe dá vida.

\begin{tabular}{|c|c|c|c|c|}
\hline Revista Didectus & Ano 9 & n. 17 & Maio - Agosto 2020 & p.258-270 \\
\hline
\end{tabular}


Desse modo, o autor destaca o equilíbrio entre as partes que constituem o capital produtivo para esclarecer as cisões qualitativa e quantitativa decorrentes do estágio D-M, isto é, da transformação do dinheiro em mercadoria. A primeira fase do capital monetário cumpre seu papel na circulação garantindo a medida ideal entre meios de produção $\mathrm{Mp}$ e força de trabalho $\mathrm{T}$, capital constante e capital variável, trabalho morto e trabalho vivo, ou seja, imprime à produção burguesa uma correspondência entre os elementos de sua composição orgânica mediante o tempo de trabalho não pago. Obediente à lógica de exposição categorial, Marx desconsidera a assimetria proveniente da acumulação capitalista, enunciada na seção VII do livro I enquanto manifestação estrutural do processo de valorização do valor, e sublinhada na seção III do livro III como corolário da disputa pelo controle do mercado mundial e fundamento da queda tendencial da taxa de lucro.

\footnotetext{
Até que ponto o emprego do trabalho excedente provoca, em diferentes ramos da indústria, um incremento de valor em forma de meios de produção é aqui totalmente indiferente. O que importa é que a parte do dinheiro investida em meios de produção - os meios de produção comprados em D $\mathrm{Mp}$ - seja, sob quaisquer circunstâncias, suficiente; que ela seja, portanto, calculada de antemão, obtida na devida proporção. Em outras palavras, a massa dos meios de produção tem de ser suficiente para absorver a massa de trabalho, e por meio desta, transformar-se em produto. Sem os meios de produção suficientes, o trabalho excedente do qual dispõe o comprador não seria aplicável; seu direito de dispor desse trabalho não serviria para nada. Se ao contrário, houvesse mais meios de produção do que trabalho disponível, eles não seriam absorvidos pelo trabalho e, portanto, não se converteriam em produto. (MARX, 2014, p. 109).
}

A transformação do dinheiro em mercadoria garante ao burguês o controle sobre uma massa de valor cuja grandeza supera o montante destinado à compra dos meios de produção Mp e da força de trabalho $\mathrm{T}$, portanto a metamorfose originária do capital monetário corresponde à gênese da reprodução ampliada. No mesmo sentido, diz Marx (2014, p. 110): “O valor por ele adiantado na forma-dinheiro [Geldform] encontra-se agora, portanto, numa forma natural, em que ele, como valor prenhe de mais-valor (na forma de mercadorias), pode ser realizado".

Enquanto objetivação da substância que dá vida ao capital, o dinheiro corresponde ao quantum de valor que deve ser antecipado e retornar ao final do ciclo monetário mediante o cumprimento de todos os seus desígnios, pois, conforme Marx destacou (2014, p. 110), "na fase do ciclo que ora analisamos, o dinheiro aparece,

\begin{tabular}{|c|c|c|c|c|}
\hline Rovista Q Dialectus & Ano 9 & n. 17 & Maio - Agosto 2020 & p.258-270 \\
\hline
\end{tabular}


portanto, como o primeiro suporte do valor de capital e, por conseguinte, o capital monetário como a forma em que o capital é adiantado".

O dinheiro, embora seja a expressão de valor comum ao universo das mercadorias e apresente mais inconvenientes do que Maritornes ${ }^{4}$, é capital apenas em forma de potência, uma vez que seu poder social se torna mediação do sistema capitalista sob condições determinadas. O que transforma o dinheiro em capital é seu lugar no movimento da economia moderna, isto é, sua subordinação à lógica da produção burguesa. Ao considerarmos o ciclo do capital monetário, atribuímos ao dinheiro um nexo determinado pela fórmula D-M...P...M'-D', portanto deduzir o capital do dinheiro consistiria numa abstração comum à filosofia especulativa, cujas categorias são hipostasiadas da história.

Por outro lado, o valor de capital na condição de dinheiro está limitado a desempenhar exclusivamente funções próprias do dinheiro. O que transforma estas em funções do capital é seu papel determinado no movimento do capital e também, portanto, o nexo entre a fase em que elas aparecem e as outras fases de seu ciclo. Por exemplo, no caso em questão, o dinheiro é convertido em mercadorias, cuja combinação constitui a forma natural do capital produtivo, forma essa que, portanto, já traz em si de modo latente, isto é, conforme seja possível, o resultado do processo capitalista de produção. (MARX, 2014, p. 110).

A transformação do dinheiro em mercadoria, conforme foi esclarecido anteriormente, apresenta uma cisão qualitativa e quantitativa, uma vez que o montante destinado à composição do capital produtivo é convertido em força de trabalho $\mathrm{T}$ e meios de produção Mp. Como ocorre em toda metamorfose da mercadoria, compra e venda representam momentos distintos cuja execução pressupõe a unidade do processo, isto é, a complementaridade. Vejamos como a fórmula D-M se decompõe no mercado de trabalho: o que para o comprador é D-T, aquisição da força de trabalho mediante o uso do dinheiro, para o vendedor é T-D, venda da força de trabalho e obtenção do meio necessário à sua subsistência, portanto D-M é, inversamente, M-D. Para o capital, a troca corresponde ao primeiro estágio do processo de acumulação; para o proletariado, o início da maldição de Sísifo.

4 Marx se refere ao dinheiro no capítulo 2 do livro I fazendo alusão ao personagem da obra Dom Quixote, de Miguel de Cervantes.,

\begin{tabular}{|l|l|l|l|l|}
\hline Q Rovista Dialectus & Ano 9 & n. 17 & Maio - Agosto 2020 & p.258-270 \\
\hline
\end{tabular}


Sendo assim, o circuito D-T equivale à metamorfose do capital monetário em força de trabalho, isto é, capital que produz valor excedente, uma vez que a espoliação é conditio sine qua non à acumulação capitalista. Trata-se de um momento singular da série D-M, pois o dinheiro, enquanto substrato do valor, permitirá a aquisição da única mercadoria capaz de fornecer a substância que dá vida ao capital.

D-T é o momento característico da transformação de capital monetário em capital produtivo, pois é a condição essencial para que o valor adiantado em forma-dinheiro se realize em capital, ou seja, transforme-se em valor que produz mais-valor. D-M é necessário apenas para realizar a massa de trabalho comprada mediante D-T. (MARX, 2014, p. 111).

A decomposição da fórmula D-M no mercado de trabalho, isto é, a metamorfose do capital monetário em capital produtivo é própria da economia burguesa devido ao seu conteúdo: entrega de trabalho excedente ou capitalização do valor. A troca entre capital e trabalho mediada pelo dinheiro corresponde estritamente à forma pela qual o valor percorre o circuito D-T, portanto o salário consiste apenas na forma disfarçada da exploração capitalista, uma vez que o montante recebido pelo trabalhador lhe garante consumir apenas o necessário à sua subsistência. Agregada aos meios de produção, a força de trabalho deve cumprir sua atribuição determinada pelo capital: manter o funcionamento de um sistema parasitário, necessariamente desigual e estruturalmente contraditório. Conforme declarou Marx (2014, p. 113), "assim que, por meio de sua venda, a força de trabalho é posta em contato com os meios de produção, ela se transforma numa parte constitutiva do capital produtivo de seu comprador, tanto quanto os meios de produção".

Obediente à condenação registrada na Bíblia, isto é, ao castigo decorrente do pecado original, a economia burguesa reserva ao proletariado o suplício da mitologia judaico-cristã em virtude de sua acumulação parasitária, isto é, da espoliação subjacente ao seu desenvolvimento. Embora fundamentado supostamente na igualdade, o germe do circuito D-T bem como sua reprodução cíclica consistem na exploração.

A relação de classe entre capitalista é assalariado já está dada, pressuposta, no momento em que os dois se confrontam na operação D-T (T-D, do lado do trabalhador). Ela é compra e venda, relação monetária, mas uma compra e venda em que o comprador é pressuposto como capitalista e o vendedor como trabalhador assalariado, e que se baseia no fato de as condições necessárias à realização da força de trabalho - meios de subsistência e meios

\begin{tabular}{|c|c|c|c|c|}
\hline Rovista Dialectus & Ano 9 & n. 17 & Maio - Agosto 2020 & p.258-270 \\
\hline
\end{tabular}


de produção - estarem apertadas, como propriedade alheia, do possuidor dessa força de trabalho. (MARX, 2014, p. 113).

A extração do mais-valor, isto é, o tempo de trabalho excedente usurpado na produção, pressupõe a relação entre compra e venda subjacente ao processo de circulação: a exploração proletária, enquanto elemento constitutivo do capital produtivo, representa a materialização do cinismo burguês, a pilhagem acarretada pela igualdade formal entre capital e trabalho. Se a produção determina a circulação mediante a espoliação operária, reproduzindo o pauperismo que lhe é estrutural, a circulação determina a produção segundo a paridade ilusória do direito burguês.

\begin{abstract}
A relação de capital durante o processo de produção só surge porque ela já existe, em si mesma, no ato de circulação, nas diferentes condições econômicas fundamentais em que o comprador e o vendedor se defrontam um com o outro, em sua relação de classe. Não é o dinheiro que, pela própria natureza, engendra essa relação, mas, antes, é a existência dessa relação que pode transformar uma simples função do dinheiro numa função do capital. (MARX, 2014, p. 114).
\end{abstract}

O nexo entre capital e trabalho mediante o poder social do dinheiro é concebido pelo autor como aspecto formal de um processo estruturalmente contraditório, portanto a economia monetária é mero desdobramento de uma sociedade que, em última instância, produz para a troca. Conforme foi esclarecido anteriormente, transformar o dinheiro no demiurgo da produção capitalista é um devaneio comum à filosofia especulativa, cujo procedimento inverte a relação entre sujeito e objeto, concebe a legalidade da coisa segundo a arbitrariedade do pensar e despreza o conjunto de determinações resultante do processo histórico. Desse modo, a decomposição do capital monetário no mercado de trabalho, isto é, o cumprimento da série D-T, apresenta, em geral, duas distorções paralelas, conforme diz Marx a seguir:

Na concepção do capital monetário (este só nos interessa, por ora, no interior da função determinada em que ele se apresenta aqui) costumam ter lugar dois erros paralelos ou amalgamados. Primeiramente: as funções que o valor de capital exerce como capital monetário e que ele pode exercer precisamente por se encontrar na forma-dinheiro são erroneamente deduzidas de seu caráter de capital, ao passo que elas se devem apenas à condição de dinheiro do valor de capital, à sua forma de manifestação como dinheiro. E em segundo lugar, inversamente: o conteúdo específico da função de dinheiro, que faz dela ao mesmo tempo uma função do capital, é deduzido da natureza do dinheiro (confundindo-se, assim, dinheiro com capital), quando na

\begin{tabular}{|l|l|l|l|l|}
\hline Q Povista Dialectus & Ano 9 & n. 17 & Maio - Agosto 2020 & p.258-270 \\
\hline
\end{tabular}


realidade tal conteúdo pressupõe condições sociais - como, nesse caso, na operação D-T - que não estão de modo algum dadas na circulação simples de mercadorias e na correspondente circulação de dinheiro. (MARX, 2014 p. 114).

A execução do circuito D-T, isto é, a compra da força de trabalho mediante o poder social do dinheiro, pressupõe a dissociação entre produtores e seus meios de subsistência, portanto a distribuição excludente dos elementos necessários à produção é imprescindível à circulação do capital monetário. Segundo Marx (2014, p. 115), "para que a operação D-T possa tornar-se um ato social geral, é preciso que os meios de produção, a parte objetiva do capital produtivo, já existam enquanto tais - isto é, como capital - diante do trabalhador", ou seja, o trabalho assalariado emerge de um processo que, através da espoliação visceral, negou autonomia aos produtores, reuniu uma massa de indigentes nos centros industriais da Europa e criou o germe da acumulação capitalista.

Conforme foi apresentado, a transformação do dinheiro em mercadoria representa a série embrionária do capital monetário, mas o circuito D-M é, inversamente, M-D, portanto, em sua interdependência, compra e venda constituem a unidade da circulação. Sendo assim, a paralisação momentânea do valor é consumada na troca, pois o cumprimento da série D-M resulta na decomposição do dinheiro em meios de produção e força de trabalho, isto é, em capital produtivo. Segundo Marx (2014, p. 117), "o primeiro estágio, a transformação do capital monetário em capital produtivo, aparece apenas como precursor e fase introdutória do segundo estágio, da função do capital produtivo".

A transformação do dinheiro em mercadoria equivale, para o trabalhador, exatamente o seu oposto: se a compra é representada pela série D-T, aquisição da força de trabalho mediante o poder social do dinheiro, a venda corresponde à inversão que lhe é decorrente, T-D. No mesmo sentido, diz Marx (2014, p. 117): "Diante do trabalhador, o capitalista tem de atuar constantemente como capitalista monetário, e seu capital tem de confrontá-lo como capital monetário". O primeiro estágio do capital monetário representa, para o proletariado, o início de sua deterioração: submetido à sordidez do capital e reduzido à condição fisiológica, o operário recebe o equivalente à sua subsistência, cuja finalidade, sob o prisma da acumulação parasitária, consiste na reprodução em escala social do pauperismo subjacente ao trabalho assalariado.

\begin{tabular}{|l|l|l|l|l|}
\hline Qevista Dialectus & Ano 9 & n. 17 & Maio - Agosto 2020 & p.258-270 \\
\hline
\end{tabular}




\begin{abstract}
Por outro lado, porém, para que a massa dos produtores diretos, os trabalhadores assalariados, possa realizar a operação T-D-M, é preciso que ela encontre constantemente os meios de subsistência em forma comparável, isto é, em forma de mercadorias. Essa situação requer um alto grau de circulação dos produtos como mercadorias e, portanto, do desenvolvimento da produção mercantil. Tão logo a produção por meio do trabalho assalariado esteja generalizada, a produção de mercadorias deve se tornar a forma geral da produção. (MARX, 2014, p. 117-118).
\end{abstract}

A reposição da força de trabalho pressupõe a aquisição dos meios de subsistência em forma de mercadoria pelo proletariado, portanto a troca, determinação estrutural e progressiva da economia capitalista, é imprescindível à execução do circuito D-T, que por sua vez é conditio sine qua non à produção mercantil. Desse modo, a condenação proletária ao trabalho degradante emana da íntima relação entre o trabalho assalariado e a ampla circulação de mercadorias. Como um carrasco impiedoso, o capital sacrifica lentamente sua vítima, destrói formas alternativas de existência material, transforma a história num registro de sua acumulação devastadora e proclama sua tirania pelos confins do universo.

As mesmas circunstâncias que produzem a condição fundamental da produção capitalista - a existência de uma classe de trabalhadores assalariados - exigem que toda produção de mercadorias se transforme em produção capitalista de mercadorias. À medida que esta última se desenvolve, ela exerce um efeito destrutivo e dissolvente sobre todas as formas anteriores de produção, que, voltadas preferencialmente à satisfação das necessidades imediatas do produtor, só convertem em mercadoria as sobras do que foi produzido. Ela faz da venda do produto o interesse primordial, sem que, de início, isso pareça afetar o próprio modo de produção, o que, por exemplo, constitui o primeiro efeito do comércio capitalista mundial sobre povos como o chinês, o indiano, o árabe etc. Em segundo lugar, porém, onde lança raízes, ela destrói todas as formas da produção de mercadorias baseadas seja no trabalho dos próprios produtores, seja meramente na venda dos produtos excedentes como mercadorias. Primeiramente ela universaliza a produção de mercadorias e, então, transforma gradualmente toda a produção de mercadorias em produção capitalista. (MARX, 2014, p. 118).

Após a execução do circuito D-M, o processo de circulação é interrompido devido ao funcionamento do capital produtivo, portanto o dinheiro cumpre seu dever enquanto equivalente universal e reúne os elementos necessários à produção capitalista para reaparecer no mercado com uma massa de valor superior ao montante germinal do capital monetário. Vejamos de que modo isso acontece: o dinheiro, mediante o poder

\begin{tabular}{|l|l|l|l|l|}
\hline Qevista Dialectus & Ano 9 & n. 17 & Maio - Agosto 2020 & p.258-270 \\
\hline
\end{tabular}


social que lhe é atribuído, garante a simbiose entre meios de produção Mp e força de trabalho T, cuja finalidade é ampliar o quantum de valor embrionário; do metabolismo entre capital constante e capital variável, resulta o mais valor objetivado no capitalmercadoria; por fim, o cumprimento da série $\mathrm{M}^{\prime}-\mathrm{D}^{\prime}$ representa a última etapa do processo de valorização do valor.

Desse modo, identificar a origem do lucro na troca consiste num quiproquó cuja elaboração se deve à economia política clássica, pois, conforme destacou Marx (2014, p. 120): "A mercadoria se torna capital-mercadoria [Warenkapital] como forma de existência funcional do valor de capital já valorizado e surgida diretamente do próprio processo de produção". A forma capital-mercadoria equivale à soma dos elementos consumidos durante a produção mais o tempo de trabalho usurpado pela classe dominante, portanto a massa de valor contida em $\mathrm{M}$ ' corresponde a "P + M, isto é, ao valor do capital produtivo P consumido em sua produção mais o mais-valor por ele gerado", conforme diz Marx (2014, p. 120) ao descrever a equação resultante da exploração capitalista.

O capital-mercadoria, resultante da composição entre meios de produção

Mp e força de trabalho $\mathrm{T}$, isto é, das forças produtivas que mantêm a acumulação burguesa, deve cumprir o circuito $\mathrm{M}^{\prime}-\mathrm{D}^{\prime}$ mediante uma nova metamorfose, pois se o início do processo de valorização do valor consiste em D-M, o desfecho corresponde ao seu oposto. Segundo Marx (2014, p. 122), "a função de M' é, agora, a função de todo produto-mercadoria: converter-se em dinheiro, ser vendida, percorrer a fase de circulação M-D". Como um parasita insaciável, o capital absorve do hospedeiro a substância que garante seu impulso vital aguardando seu metabolismo instantâneo, pois a massa de valor contida na mercadoria deve converter-se rapidamente em capital monetário. No mesmo sentido, diz Marx (2014, p. 122): “Enquanto o capital já valorizado conserva-se em sua forma do capital-mercadoria, permanecendo imóvel no mercado, o processo de produção fica paralisado. O capital não atua nem como criador de produtos, nem como criador de valor."

A execução da série M'-D' representa o último estágio do capital monetário, uma vez que a massa de valor lançada no mercado através do dinheiro retorna ao início do circuito com uma grandeza superior, cuja finalidade é obedecer o processo de valorização do valor. Segundo Marx (2014, p. 124), "ao completar-se o ato de M'-D',

\begin{tabular}{|l|l|l|l|l|l|} 
Gevista Dialectus & Ano 9 & n. 17 & Maio - Agosto 2020 & p.258-270 \\
\hline
\end{tabular}


realiza-se tanto o valor de capital adiantado quanto o mais-valor. A realização de ambos se dá na sequência de vendas ou na venda, de um só golpe, da massa inteira de mercadorias expressa por M'-D'".

Enquanto a última série do capital monetário corresponde, para o mais valor, o início do processo de circulação, para o montante germinal equivale à etapa derradeira, portanto o salto mortal da mercadoria representa estágios distintos para o quantum de trabalho usurpado durante o capital produtivo e a massa de valor que dá origem ao processo acumulação burguesa. No mesmo sentido, diz Marx (2014, p. 124): "O que para o mais-valor é a primeira transmutação da forma-mercadoria em formadinheiro para o valor de capital é o retorno ou a reconversão a sua forma-dinheiro original".

O cerne do processo de expansão capitalista, isto é, a diferença entre a grandeza de valor materializada no dinheiro e o quantum de trabalho incorporado no capital-mercadoria reside na simbiose entre as forças produtivas reunidas pela economia capitalista. O metabolismo entre meios de produção $\mathrm{Mp}$ e força de trabalho $\mathrm{T}$ interrompe a circulação, amplia a massa de valor germinal e cumpre sua função no ciclo do capital monetário, cuja finalidade é obter uma diferença quantitativa entre seus extremos preservando seu caráter qualitativo.

\begin{abstract}
O processo de produção aparece, assim, apenas como uma interrupção do processo de circulação do valor de capital, que até o momento só percorreu sua primeira fase D-M. Ele percorre a segunda e conclusiva fase M-D depois de $\mathbf{M}$ ter sido modificada em sua matéria e seu valor. Porém, quando se considera o valor de capital em si mesmo, vê-se que ele sofreu apenas uma alteração de sua forma de uso no processo de produção. (MARX, 2014, p. $125)$.
\end{abstract}

O montante germinal do capital monetário, cuja finalidade reside na compra de meios de produção Mp e força de trabalho T mediante o poder social do dinheiro, apresentará a mesma grandeza ao final do processo de acumulação percorrendo estágios mutuamente complementares, pois a transformação do dinheiro em mercadoria, isto é, a execução do circuito D-M, é simultaneamente seu oposto, venda do capital-mercadoria e cumprimento da passagem M-D. Assim, os extremos do ciclo correspondente ao processo de valorização do valor são perfeitamente idênticos, uma vez que suas determinações qualitativa e quantitativa permanecem iguais.

\begin{tabular}{|l|l|l|l|l|}
\hline Q Povista Dialectus & Ano 9 & n. 17 & Maio - Agosto 2020 & p.258-270 \\
\hline
\end{tabular}


A diferença entre a massa de valor embrionária do capital monetário e o resultado de sua metamorfose conclusiva é decorrente do tempo de trabalho não pago, da espoliação que garante o impulso vital da economia capitalista, portanto a série M'-D' representa conjuntamente a grandeza de valor primária mais o excedente obtido durante a produção.

\begin{abstract}
A forma-dinheiro desempenha aqui, portanto, um duplo papel; por um lado, é a forma retomada de um valor originalmente adiantado em dinheiro, logo, o retorno à forma-valor que dá início ao processo; por outro, é a primeira forma transmutada de um valor que entra originalmente na circulação da forma da mercadoria. (MARX, 2014, p. 125).
\end{abstract}

Após o cumprimento de todos os seus desígnios, o capital monetário reaparece com um novo quantum, cujo fundamento, conforme foi dito anteriormente, reside na espoliação proletária. Obediente às leis que regem a produção capitalista, a classe dominante transforma o dinheiro resultante da metamorfose M'-D' na largada de um novo ciclo da acumulação capitalista. Segundo Marx (2014, p. 126), "D não aparece mais como mero dinheiro, mas funciona expressamente como capital monetário, expresso como valor que se valorizou e que, portanto, possui também a propriedade de se valorizar, de criar mais valor do que o que ele mesmo tem".

O cumprimento do circuito D...D' equivale, de forma resumida, ao processo de acumulação imanente à economia burguesa, de modo que a diferença entre o montante germinal e o mais valor resultante da série $\mathrm{M}^{\prime}-\mathrm{D}^{\prime}$ desvanece, surgindo uma identidade absoluta entre as partes constitutivas do capital valorizado. Enquanto forma sem-conceito, D' é pura abstração, hipostasiado de suas determinações ou destituído de conteúdo, pois ao desconsiderar o processo que lhe dá existência, isto é, a combinação das mercadorias particulares, o quantum de valor obtido mediante a execução da série M'-D' é completa indiferença. Conforme destacou Marx (2014, p. 127), "no dinheiro, toda distinção entre as mercadorias é apagada porque ele é justamente a forma equivalente comum a todas elas".

A relação de equivalência entre os agentes de mercado durante o processo de circulação do capital, isto é, o escambo mediado pelo poder social do dinheiro, consiste no fundamento da igualdade que mistifica o cerne da economia burguesa. Embora haja uma paridade no regime de trocas, seja na aquisição dos elementos

\begin{tabular}{|l|l|l|l|l|}
\hline Gevista Dialectus & Ano 9 & n. 17 & Maio - Agosto 2020 & p.258-270 \\
\hline
\end{tabular}


necessários à produção ou na venda da mercadoria resultante do metabolismo entre meios de produção Mp e força de trabalho T, a exploração decorrente da diferença entre o valor produzido pelo trabalho e o salário pago ao trabalhador é mantida em virtude do caráter parasitário de um sistema que aumenta sua riqueza sem diminuir sua miséria. Como Henry de Marsay ${ }^{5}$, o capital age com cinismo ao se apresentar de forma elegante e cordial na esfera da circulação para, em seguida, condenar os trabalhadores ao martírio profano.

\begin{abstract}
Aqui resulta, ademais, que nas duas metamorfoses que ocorrem na circulação, D-M e M'-D', confrontam-se e substituem-se mutuamente valores de mesma grandeza e que existem simultaneamente. A alteração de valor pertence exclusivamente à metamorfose $\mathrm{P}$, ao processo de produção, que assim aparece como metamorfose real do capital, diante das metamorfoses meramente formais da circulação. (MARX, 2014, p. 131).
\end{abstract}

O capital industrial, cujo funcionamento destrói ou submete outras formas de existência material devido à sua acumulação despudorada, é o responsável pelo próprio movimento da economia burguesa. No mesmo sentido, diz Marx (2014, p. 134): "Esse capital condiciona, portanto, o caráter capitalista da produção; sua existência inclui a existência da oposição de classes entre capitalista e trabalhadores assalariados". Embora a existência do dinheiro seja anterior à produção capitalista, o ciclo do capital monetário, cujos extremos obedecem ao processo de valorização do valor conservando a identidade na diferença, consiste apenas num epifenômeno do capital industrial.

Os dois extremos equivalentes ao ciclo do capital monetário correspondem à síntese da acumulação burguesa, portanto o impulso vital da produção capitalista pode ser resumido da seguinte maneira: o dinheiro, enquanto substrato necessário da forma valor, cumpre o processo de circulação ampliando sua grandeza sem abandonar seu conteúdo. Segundo Marx (2014, p. 136), “a criação de mais-valor por meio do valor é não apenas expresso como o alfa e o ômega do processo como também aparece concretamente na forma reluzente do dinheiro", entretanto, se considerarmos apenas a relação idêntico-diferente contida na séria D...D', a reprodução ampliada permaneceria

5 Personagem do romance de Honoré de Balzac intitulado A Menina dos Olhos de Ouro, terceiro e último volume da trilogia História dos Treze.

\begin{tabular}{|l|l|l|l|l|}
\hline Q Povista Qialectus & Ano 9 & n. 17 & Maio - Agosto 2020 & p.258-270 \\
\hline
\end{tabular}


como um mistério cuja resolução estaria confinada ao quiproquó da economia política clássica.

Como já foi demonstrado, o fundamento da autovalorização do valor consiste na espoliação proletária, isto é, no tempo de trabalho usurpado pelo capital. Essa relação parasitária só pode ser mantida enquanto o hospedeiro tiver vida, pois, conforme diz Marx (2014, p. 137), “o trabalhador, para poder se manter no mercado, sempre como matéria explorável pelo capitalista, necessita, antes de tudo, viver, isto é, sustentar-se mediante seu consumo individual". Para o trabalhador, o salário é apenas meio de garantir seus meios de subsistência ou reproduzir-se em condição animalesca, sua existência está limitada à satisfação do capital, que, após levá-lo à exaustão, exige a reposição imediata de suas capacidades para o cumprimento de seu castigo eterno. No mesmo sentido, diz Marx (2014, p. 137): “A operação T-D serve de mediação ao consumo individual do trabalhador, possibilitando a transformação dos meios de subsistência em sua carne e em seu sangue".

\section{REFERÊNCIAS}

MARX, Karl. O Capital: crítica da economia política. Livro II. São Paulo: Boitempo, 2014.

\begin{tabular}{|l|l|l|l|l|}
\hline Qovista Dialectus & Ano 9 & n. 17 & Maio - Agosto 2020 & p.258-270 \\
\hline
\end{tabular}

